\title{
CORRECTIVE ACTION Site 02-37-02 BACKGROUND INFORMATION AND COMPARISON TO CORRECTIVE ACTION SiTE 09-99-06
}

Corrective Action Site (CAS) 02-37-02, Gas Sampling Assembly, is associated with nuclear test MULLET. MULLET was an underground safety test conducted on October 17, 1963. The experiment also involved prompt sampling of particulate material from the detonation, similar to CAS 09-99-06, Gas Sampling Assembly, which is associated with PLAYER/YORK.

The sampling system at MULLET was similar to that of PLAYER/YORK and was used to convey gas from the MULLET emplacement hole (U2ag) to a sampling assembly. Beyond the sampling assembly, the system had a "Y" junction with one branch running to a filter unit and the other running to a scrubber unit. The total system length was approximately 250 feet and is depicted on the attached drawing.

According to the available background information, retrieval of the sample material from the MULLET event caused significant alpha (plutonium) contamination, limited to an area near ground zero (GZ). Test support Radiological Control Technicians did not detect contamination outside the immediate GZ area. In addition, vehicles, equipment, and workers that were contaminated were decontaminated on site. Soil contamination was addressed through the application of oil, and the site was decommissioned after the test. Any equipment that could be successfully decontaminated and had a future use was removed from the site. The contaminated equipment and temporary buildings erected to support the test were buried on site, most likely in the area under the dirt berm. The exact location of the buried equipment and temporary buildings is unknown. No information was found describing the disposition of the filter and scrubber, but they are not known to be at the site.

The COMMODORE test was conducted at U2am on May 20, 1967, and formed the crater next to CAS 02-37-02. The COMMODORE test area had been surveyed prior to the test, and alpha contamination was not identified. Furthermore, alpha contamination was not identified during the COMMODORE re-entry survey, and routine surveys around the crater lip did not identify alpha contamination.

Background information includes several radiological surveys conducted after these two tests. The MULLET area has been surveyed frequently. The early surveys indicate the area as both contaminated and containing buried radioactive material.

A survey conducted in 1970 found the radiological/chemical piping partially intact, including the "Y" junction, and shows two runs of intact piping running past the U2am crater lip. The survey focused on the piping system itself and detected alpha contamination from 4 counts per minute (cpm) to $900,000 \mathrm{cpm}$. The highest value was at a pipe flange between a dirt pile and a dirt berm within the current site fence line. All readings were direct, and no smears were taken.

A 1972 survey was essentially a repeat of the 1970 survey; however, it does not show the "Y" junction nor does it show piping extending past the U2am crater lip. It also shows a new fence line separating the radiological/chemical piping from the U2am crater area with all piping within the fence. Alpha contamination was detected on pipe flanges during the survey, but alpha contamination was not detected on the dirt pile or the dirt berm. All readings were direct, and no smears were taken.

Additional surveys were conducted in 1986, 1990, 1992, 1993, and 1996. One of the surveys focused on determining the extent of soil contamination around GZ. An alpha contamination plume extending approximately 200 feet south of GZ was detected in a swath approximately 100 feet wide. The maximum measurement was 15,000 cpm alpha. All surveys show the piping within the fence line.

Recent surveys (2007 and 2008) were performed around the current fence line by the demarcation group. No removable contamination was identified during these surveys. In late 2008, a visual inspection of the 
site was conducted by the National Security Technologies, LLC, Environmental Restoration group. All piping is within the fence line. Photos taken during this site visit are attached.

\section{Comparison of CAU 544 to CAU 547}

Based on the evaluation of the background information on CAS 02-37-02, a comparison was made to known information about CAS 09-99-06.

\section{Similarities}

- Both tests were safety tests with associated prompt particulate sampling.

- Each test involved piping running from the test cavity to the sampling apparatus with the specific intent of bringing plutonium to the surface to be sampled.

- The system design was similar as seen in the two attached as-built drawings.

- The tests were conducted within 1 year of each other, both were safety shots, both were conducted by Lawrence Livermore National Laboratory, and both had the express intent of sampling plutonium particulate at the surface.

- These similarities imply that internal piping contaminant levels will be similar in both cases. However, there is not sufficient information to ensure this is the case.

\section{Differences}

- The primary difference in the system design is that CAS 09-99-06 was piped into a post-shot hole for YORK while CAS 02-37-02 was piped into a scrubber and filter. The scrubber and filter are no longer visible at the site; however, either an inlet or outlet pipe to either the filter or the scrubber is exposed at the site, and the pipe end is open.

- The primary operational difference is that sample retrieval operations at CAS 02-37-02 are known to have caused soil contamination, while historical information does not document soil contamination associated with CAS 09-99-06.

- Soil remediation at CAS 02-37-02 included application of oil, which could contain polychlorinated biphenyls or other contaminants. CAS 09-99-06 does not include these potential contaminants.

- The external surfaces of the CAS 02-37-02 piping are known to be highly contaminated in some accessible sections of the system piping. Based on the CAS 09-99-06 piping that is observable, the piping does not appear to be externally contaminated.

- The historical documentation for CAS 02-37-02 indicates that parts of the system and site structures were demolished and material was buried on site. This is not the case at CAS 09-99-06.

\section{Conclusions}

- External surfaces of system piping at the eastern end of CAS 02-37-02 are contaminated. Historical values range from 100 to $15,000 \mathrm{cpm}$ alpha. Some external surfaces of system piping closer to GZ are more contaminated, with values as high as 900,000 cpm alpha on the external pipe flange. 
- Exposed piping to the west towards GZ appears to be partially intact with exposed, external surfaces that are highly contaminated. The unexposed inside of the pipe is expected to be contaminated at levels similar to CAS 09-99-06; however, this has not been verified.

- The dirt pile and dirt berm were likely put in place after the test to minimize contamination migration and to cover the material buried on site.

- The plume of alpha contamination may be outside of the current fence line based on an early survey. Recent surveys show that, if present, the contamination is not readily removable.

\section{Recommendations}

- Piping sections in the eastern portion of the site are open, and the interior and exterior surfaces sections should be surveyed for removable alpha contamination. In Situ Object Counting System (ISOCS) measurements should also be collected to determine isotopic content.

- Intact sections of accessible piping moving west toward GZ should be characterized using the ISOCS. Internal and external contaminant levels can be estimated by combining direct reading alpha surveys of the external pipe surface and ISOCS values. Removable levels of alpha contamination on external surfaces should also be determined.

- Additional characterization should focus on areas to the south near GZ outside of the fence where historical surveys identified soil contamination. Extent of soil contamination should be determined in this area and characterized for additional potential contaminants.

- The source term resulting from buried materials is likely small when compared to piping source term, unless the scrubber and filter unit were also buried on site. It is unlikely that historical documentation will determine whether or not the scrubber and filter were buried on site. Under a closure in place strategy, it should be assumed that those items were buried on site and through process knowledge a bounding inventory value associated with those items should be determined. If source term removal is undertaken, characterization should be performed in parallel with source term removal.

- A similar closure to CAS 09-99-06 is anticipated for this CAS 02-37-02. This would include burying aboveground features in place and investigating the presence of previously buried debris. It is anticipated that this closure is feasible for the site.

Reference herein to any specific commercial product, process, or service by trade name, trademark, manufacturer, or otherwise, does not necessarily constitute or imply its endorsement, recommendation, or favoring by the U.S. Government or any agency thereof. 


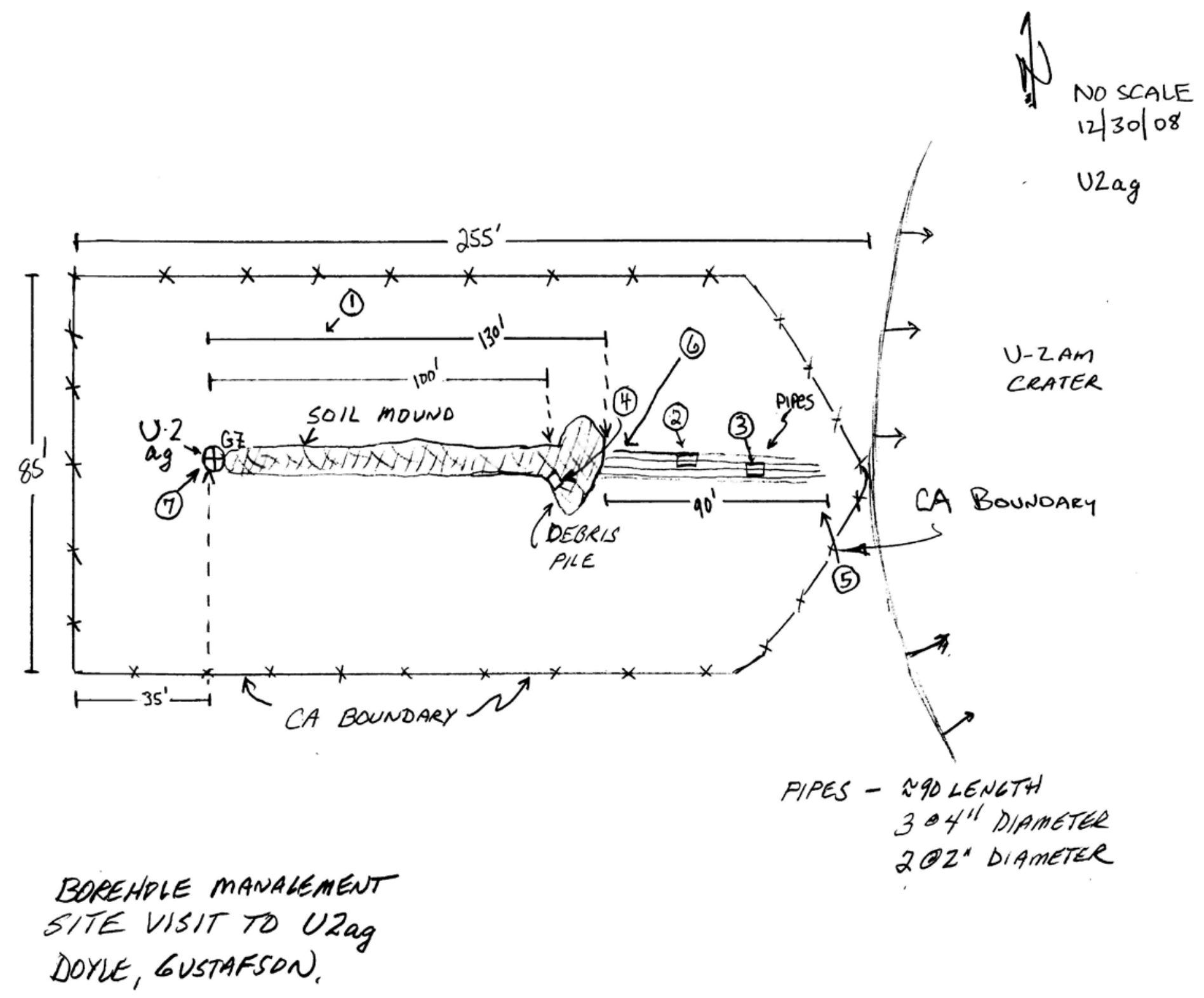


U-2ag Photo 1

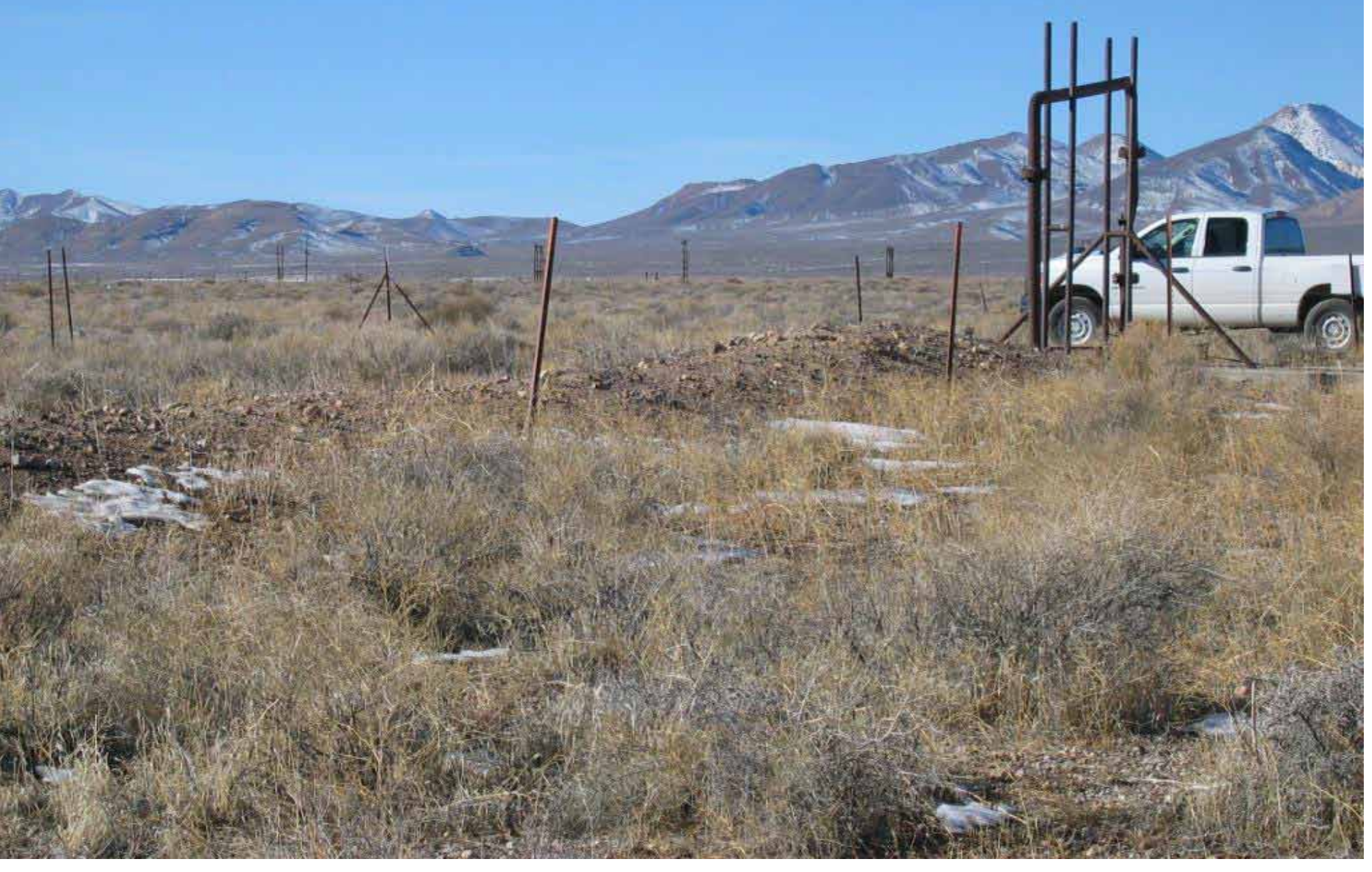




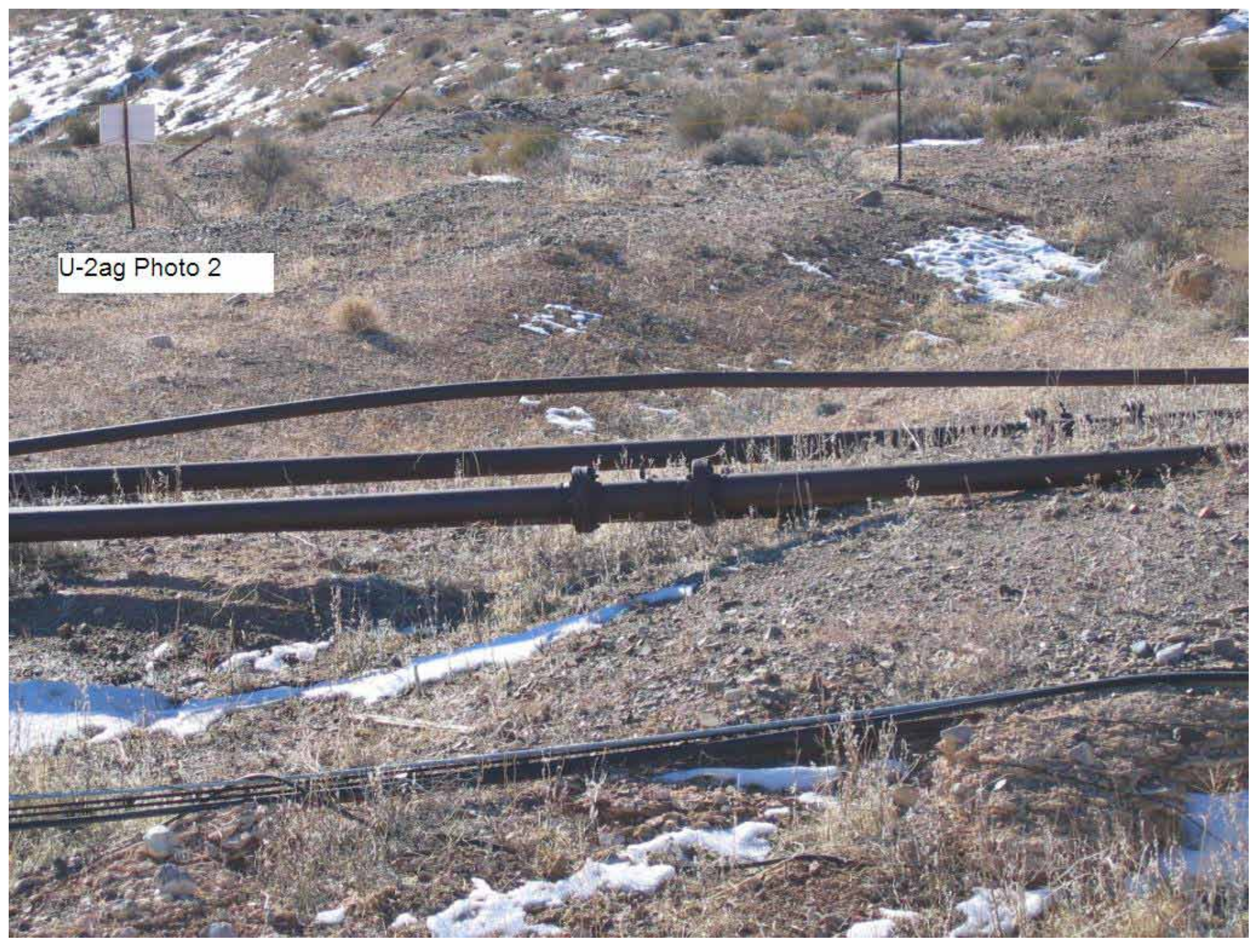




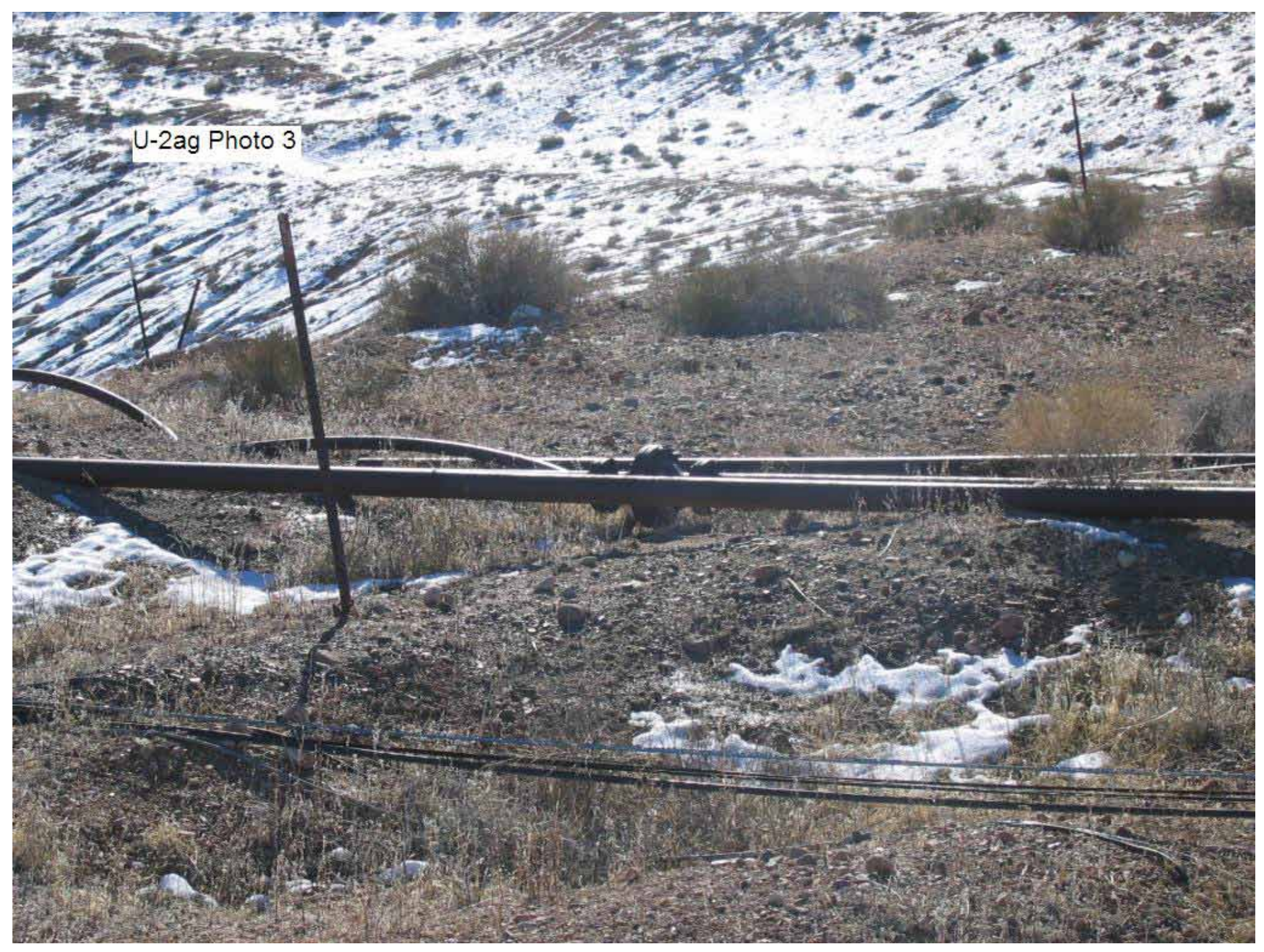


U-2ag Photo 4

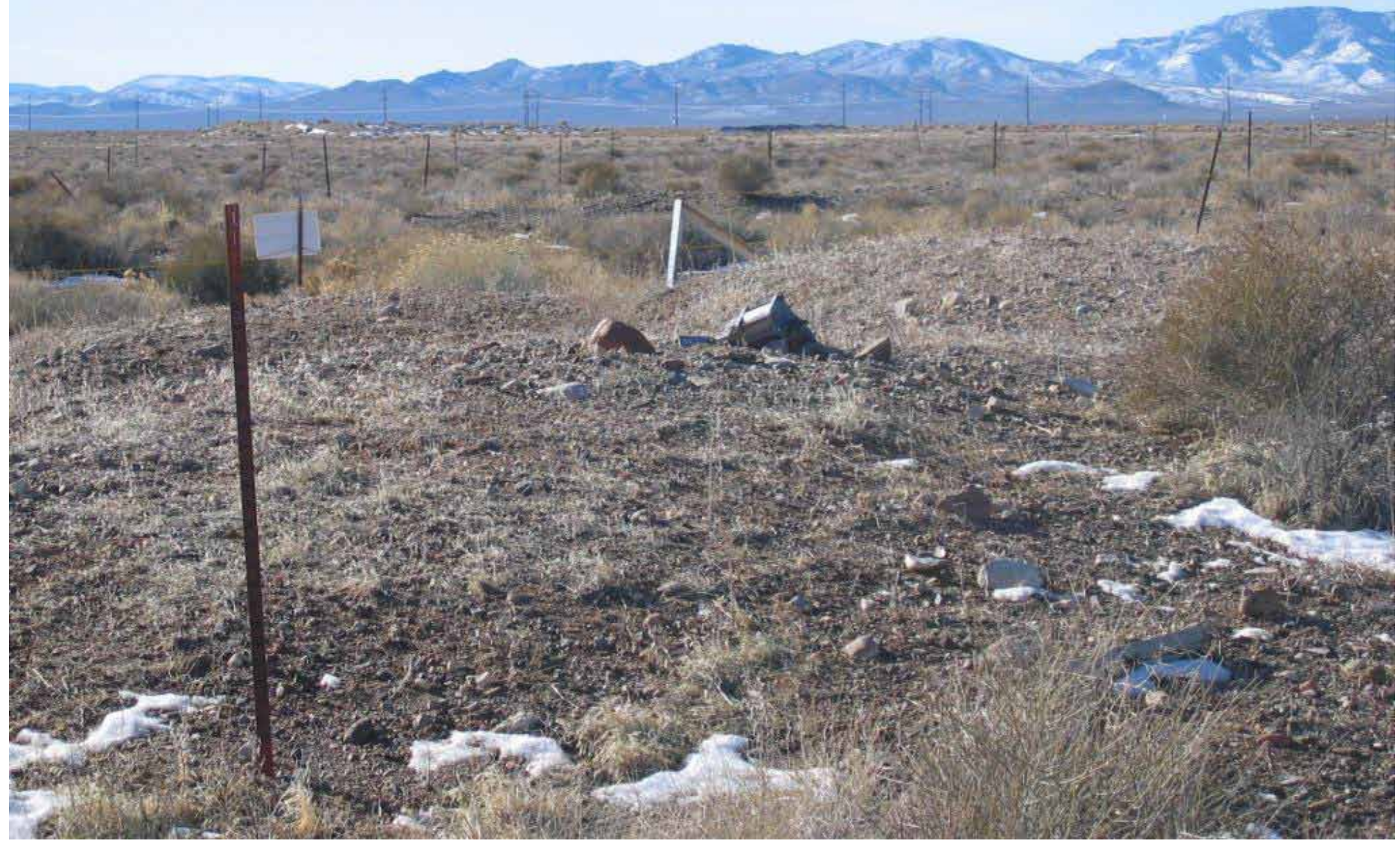




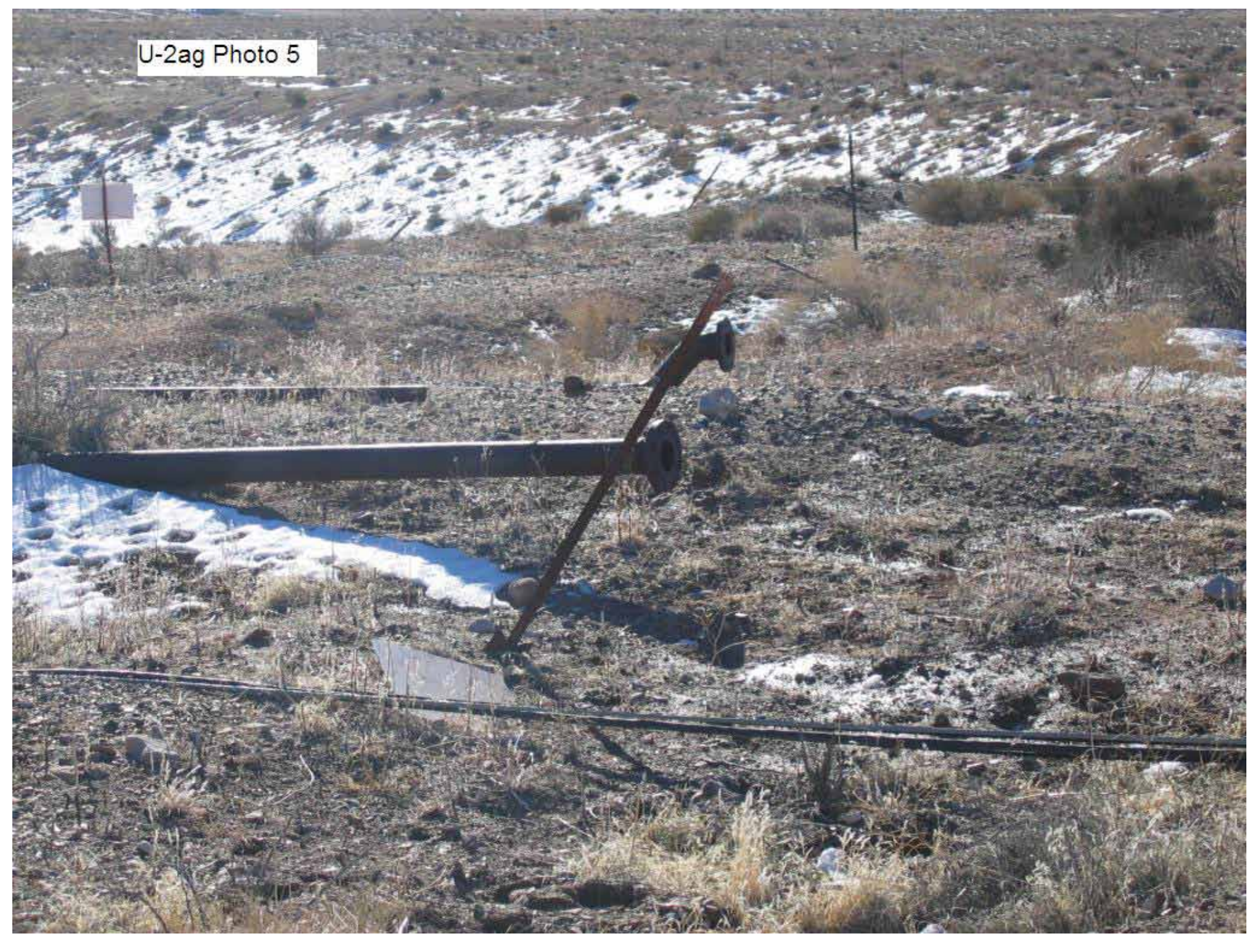


U-2ag Photo 6

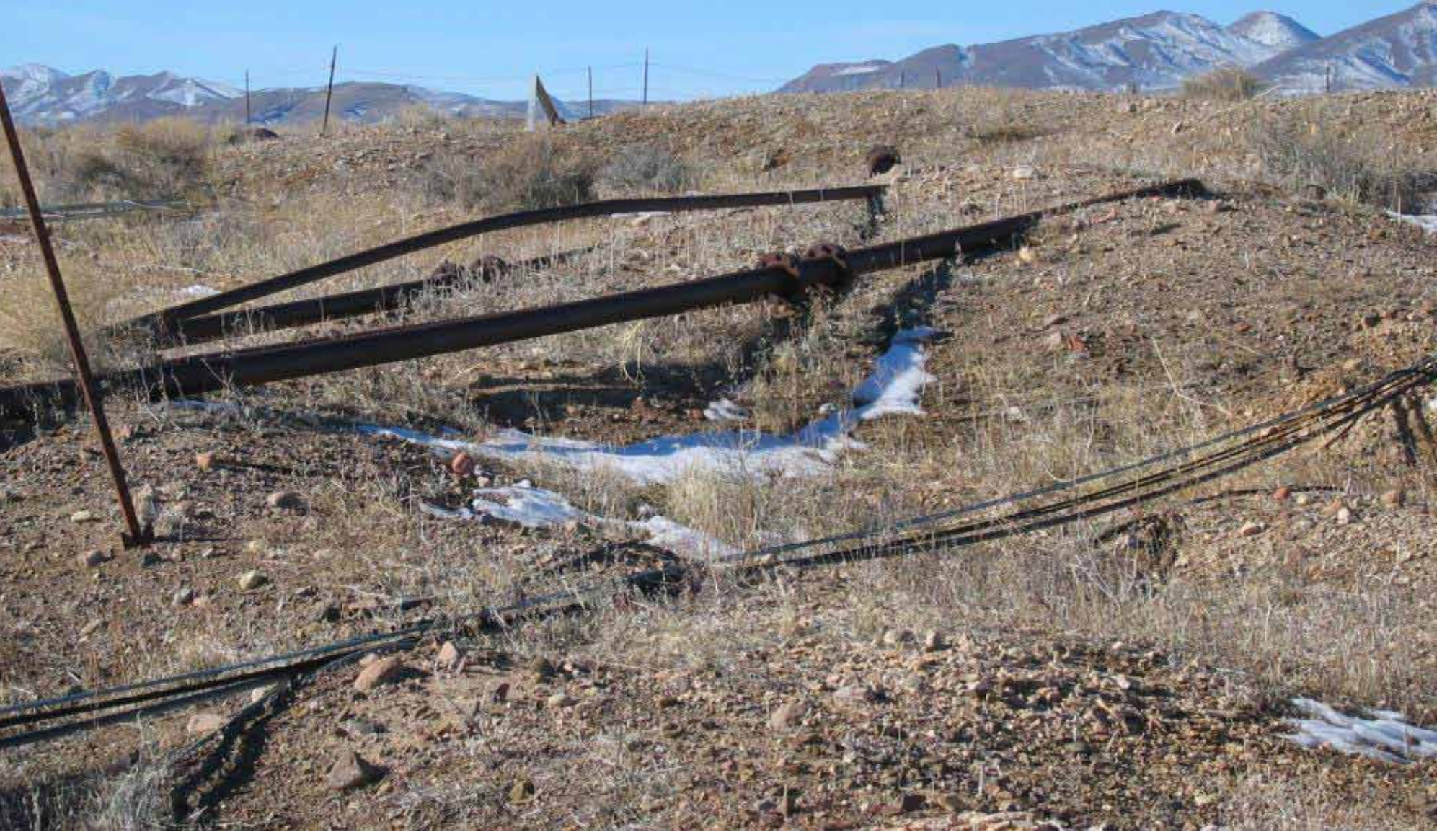


U-2ag Photo 7

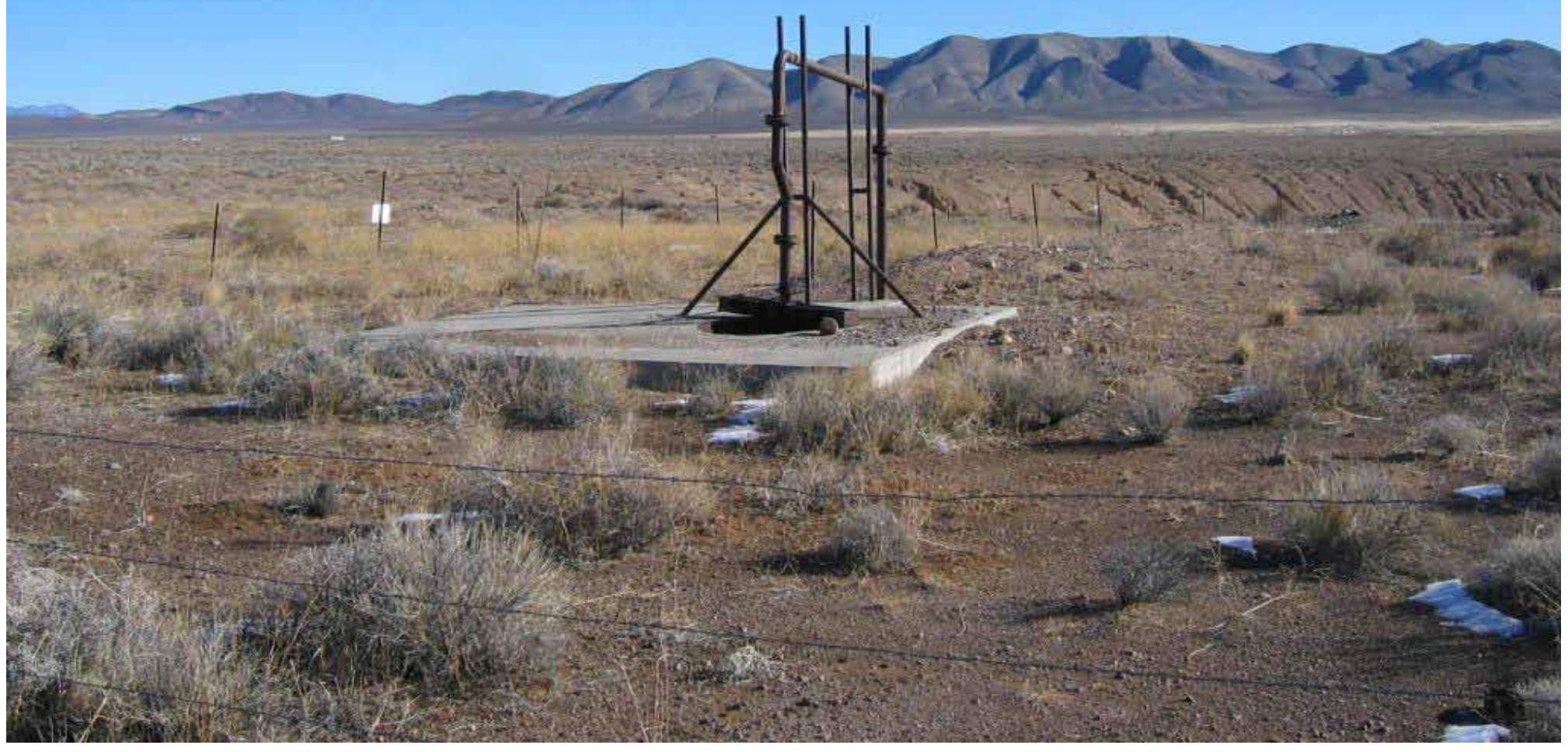




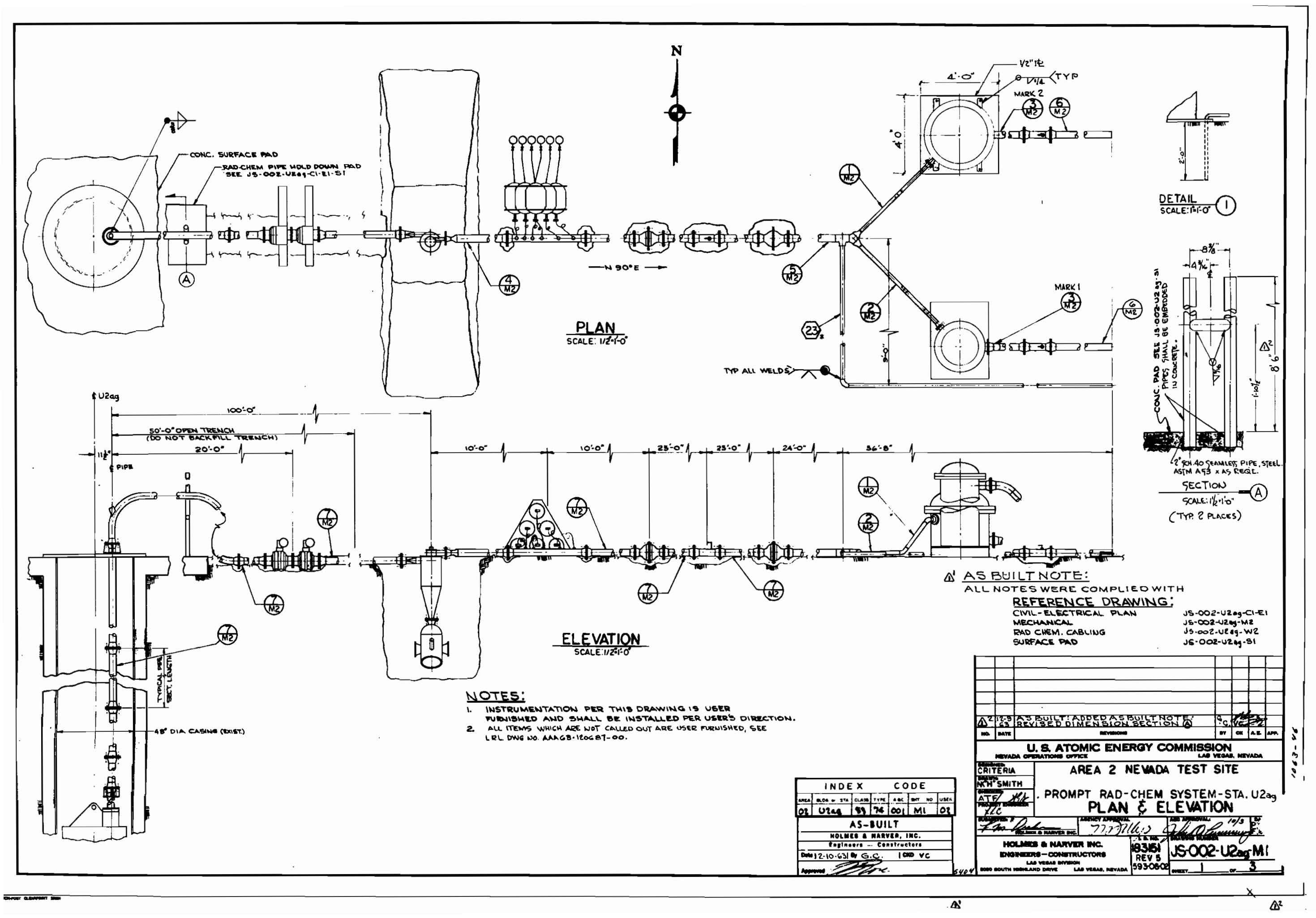




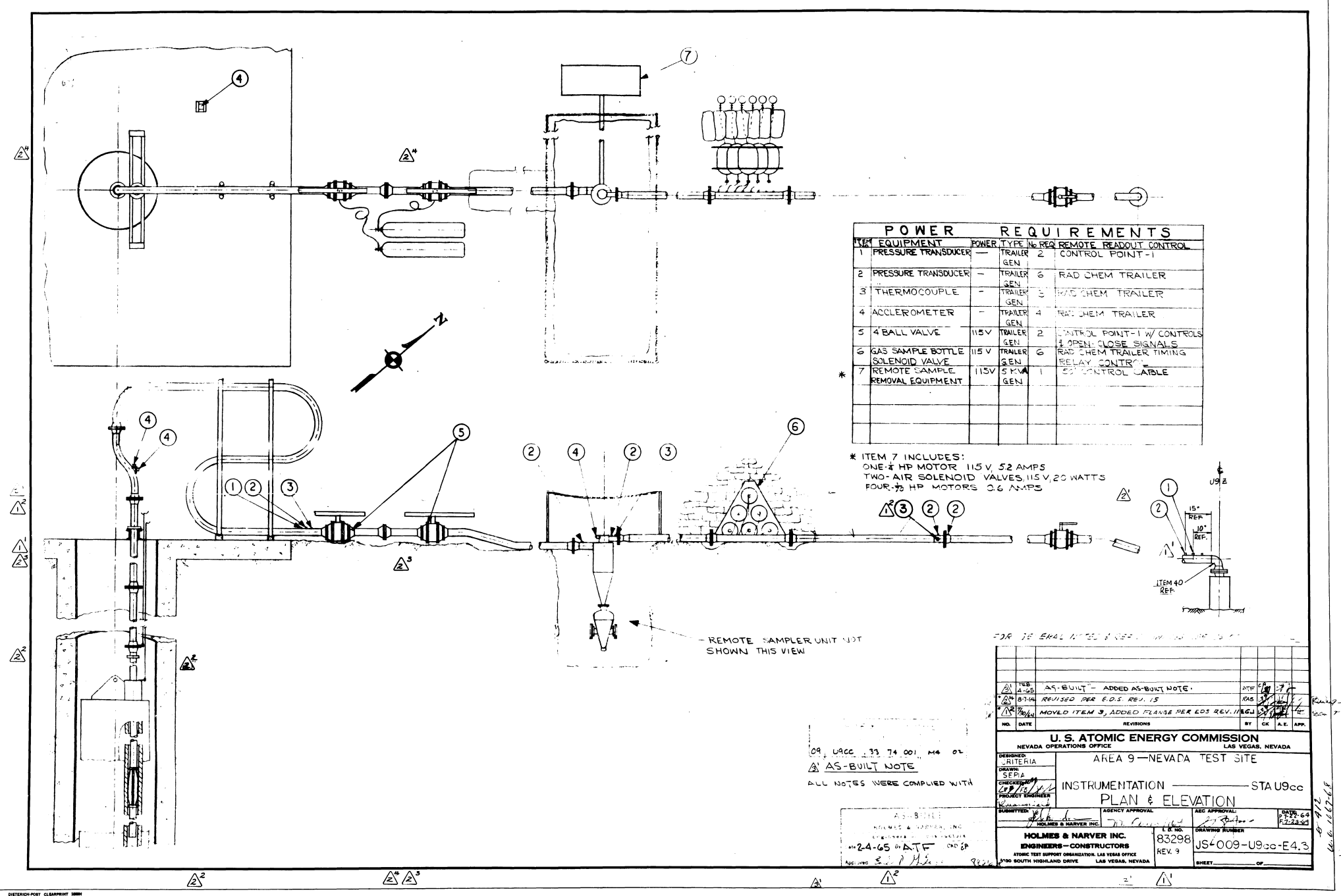

